\title{
Cross-Sensitization between Poppy Seed and Buckwheat in a Food-Allergic Patient with Poppy Seed Anaphylaxis
}

\author{
Tilmann Oppel Peter Thomas Andreas Wollenberg \\ Department of Dermatology and Allergology, Ludwig Maximilian University, Munich, Germany
}

\section{Key Words}

Cross-sensitization $\cdot$ Food allergy $\cdot$ Immunoblot inhibition - Opium $\cdot$ Challenge test, oral food

\begin{abstract}
The opium poppy, Papaver somniferum L., is the source of both poppy seeds and opium. The commercially available seeds are widely used as ingredients for various kinds of food. IgE-mediated sensitization to poppy seeds is rare, but, if present, clinical symptoms are usually severe. Cross-sensitizations between poppy seeds and other food allergens have been described with sesame, hazelnut, rye grain and kiwi fruit. We report the case of a 17-year-old female with an apparently food-allergic reaction after ingestion of a poppy seed cake. Allergological workup revealed a poppy seed anaphylaxis and led to the identification of a novel cross-sensitization with buckwheat.
\end{abstract}

Copyright $\odot 2006$ S. Karger AG, Basel

\section{Introduction}

The opium poppy, Papaver somniferum L., which originated from the coast of the black sea, has been grown all over Europe for centuries and is the source of both poppy seeds and opium [1]. The commercially available seeds are widely used throughout Europe as ingredients for var- ious kinds of food, especially poppy seed cakes and poppy seed rolls. IgE-mediated sensitization to poppy seeds is a rare event. Since sensitized patients can develop severe anaphylactic symptoms, it is important to recognize poppy seed allergy. We report clinical and laboratory investigations in a patient with a grade III anaphylactic reaction, which led to the identification of a so far unknown cross-sensitization between poppy seeds and buckwheat.

\section{Case Report}

A 17-year-old female attended our clinic for diagnostic workup of an apparently food-allergic reaction. She had taken a single bite from her friend's poppy seed cake during a coffee brake 2 weeks previously. Ten minutes later, an anaphylactic reaction with nausea, heat sensation, abdominal pain and dyspnea occurred. This resulted in admission of the eventually unconscious patient to the intensive care unit. Her past medical history included oral swelling and itching following ingestion of poppy seed rolls as well as of sesame rolls for 10 years. In addition, a severe bullous allergic contact conjunctivitis had developed after she had removed her contact lenses following serving a dinner with poppy seed rolls to her family. There was no history of hay fever, asthma or atopic dermatitis.

Clinical and Laboratory Examination

Skin Prick Test and CAP-FEIA

Skin prick tests (SPT) with saline-extracted allergens from freshly ground poppy and sesame seed as well as buckwheat and brazil nut were strongly positive. Control SPT were negative in 10 patients. SPT with common inhalant allergens showed a weakly pos-

\section{KARGER}

Fax +4161306 1234 E-Mail karger@karger.ch www.karger.com
(C) 2006 S. Karger AG, Base $1018-2438 / 06 / 1402-0170 \$ 23.50 / 0$

Accessible online at: www.karger.com/iaa
Correspondence to: Dr. med. Tilmann Oppel, Klinik und Poliklinik für

Dermatologie und Allergologie, Ludwig-Maximilians-Universität München

Frauenlobstrasse 9-11, DE-80337 München (Germany)

Tel. +49895160 6010, Fax +49 8951606312

E-Mail tilmann.oppel@med.uni-muenchen.de 


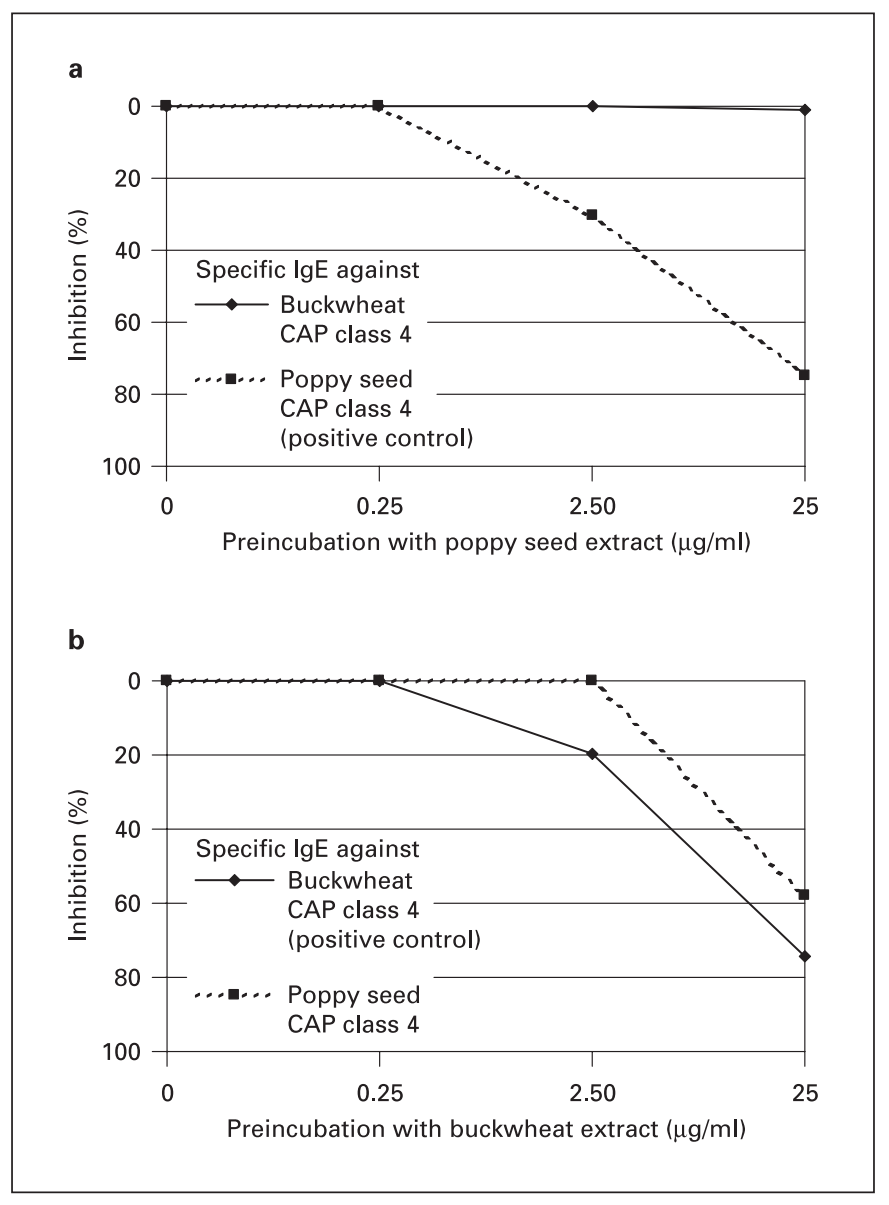

Fig. 1. CAP inhibition test. a Preincubation of the patient's serum with poppy seed extract did not inhibit the buckwheat CAP-FEIA. b Inhibition of poppy seed CAP-FEIA by buckwheat extracts demonstrates cross-reaction of poppy seed and buckwheat proteins. An inhibition of the buckwheat CAP with buckwheat extract served as a positive control (solid line).

itive reaction to grass pollen, rye pollen and hazelnut without clinical relevance. SPT with common food allergens, including avocado, kiwi, tomato, peach, pineapple, green pepper, condurango, and natural rubber latex, were all negative. SPT with native plant serum of $P$. somniferum $\mathrm{L}$. was negative.

Total serum IgE was raised to $646 \mathrm{kU} / 1$. Allergen-specific IgE against poppy seed (287 kU/1; CAP class 6), hazelnut (56.5 kU/l; CAP class 5), sesame (20.8 kU/1; CAP class 4), buckwheat (17.4 kU/1; CAP class 3), brazil nut (18.9 kU/1; CAP class 4), pistachio (16.3 kU/1; CAP class 3$)$, cashew nut ( $9.5 \mathrm{kU} / 1$; CAP class 3 ), almond (5.4 kU/1; CAP class 3$)$, rye pollen (2.53 kU/1; CAP class 2$)$ and grass pollen $(4.09 \mathrm{kU} / \mathrm{l}$; CAP class 3$)$ was detected by CAPFEIA (Pharmacia Diagnostics, Freiburg, Germany).

\section{Oral Food Challenge}

Oral food challenge with up to $10 \mathrm{~g}$ of unground poppy seeds caused no clinical reaction. Oral administration of $1 \mathrm{~g}$ of ground poppy seeds led to urticaria, heat sensation, pruritus, conjunctivitis and dyspnea. Following this positive oral provocation test, serum mast cell tryptase (Pharmacia Diagnostics, Freiburg, Germany) rose 3 -fold within $3 \mathrm{~h}(5.4-17.6 \mu \mathrm{g} / \mathrm{l})$ and returned to normal values after $18 \mathrm{~h}$.

\section{In vitro Experiments}

CAP Inhibition

To examine for cross-sensitizations between poppy seeds, buckwheat and opium, CAP inhibition tests were performed. One hundred microliters of the respective diluted allergen solutions were taken from commercial sources or freshly prepared from native food and preincubated overnight at $4{ }^{\circ} \mathrm{C}$ with $900 \mu$ l of the patient's serum. For poppy seed and buckwheat allergen preincubation, proteins of $1 \mathrm{~g}$ poppy seeds and $1 \mathrm{~g}$ buckwheat, respectively, were extracted in $9 \mathrm{ml} \mathrm{TCM}$ buffer, vigorously agitated and centrifuged for $10 \mathrm{~min}$ at 2,000 $\mathrm{g}$, prediluted 1:1,000 and finally diluted for overnight incubation 1:10, 1:100 and 1:1,000.

In our patient, preincubation with poppy seed extract did not inhibit the buckwheat CAP (fig. 1a), whereas preincubation with high concentrations of buckwheat extract caused inhibition of the patient's serum IgE binding to poppy seed (fig. 1b). At $25 \mu \mathrm{g} / \mathrm{ml}$ of buckwheat (final concentration), about $60 \%$ of the total binding was inhibited. Autoinhibition of both the buckwheat CAP with buckwheat extract and of the poppy seed CAP with poppy seed extract was seen as expected and served as a positive control. An unspecific IgE-scavenging effect of the allergen preparations was excluded by the analysis of total serum IgE and grass pollen-specific IgE.

In addition, cross-sensitization between poppy seeds and proteins from freshly drawn opium poppy latex milk and opium was analyzed. Neither preincubation of our patient's serum with opium latex nor with raw opium led to a detectable inhibition of our patient's poppy seed-specific IgE-CAP (data not shown).

Immunoblotting and Immunoblot Inhibition

SDS-PAGE of poppy seed extract was carried out according to Laemmli [2] in a 6\% polyacrylamide stocking gel and a $12.5 \%$ separating gel. Poppy seeds were homogenized in TCM buffer (1/3 $\mathrm{w} / \mathrm{v}$ ) and centrifuged at 20,000 rpm. The supernatants were removed and finally diluted at 1:1 and 1:2. The separated proteins were electroblotted onto a nitrocellulose membrane. After blocking with PBS containing 5\% BSA, the membrane was incubated overnight with the patient's serum. For inhibition experiments, the patient's serum was first preincubated with serial dilutions of buckwheat extracts $(0.5,1,2.5,5,10,25 \mu \mathrm{g} / \mathrm{ml})$. Bound IgE was detected with biotinylated sheep anti-human IgE antibody (Paesel + Lorei, Hanau, Germany), streptavidin alkaline phosphatase and NBT/BCIP substrate.

On the immunoblots, 4 distinct allergen bands with a size of about 15, 23, 30 and $46 \mathrm{kDa}$ were detected (fig. 2). The distinct, sharp bands suggest low glycosylation of the proteins. The $46-\mathrm{kDa}$ band corresponds nicely to the molecular weights of the major poppy seed allergen described in a recent laboratory study [3]. Preincubation of our patient's serum with $25 \mu \mathrm{g} / \mathrm{ml}$ of buckwheat extract resulted in a decrease of signal strength of the allergen-specific bands. With regard to a band-specific inhibition, it is clearly visible that all $4 \mathrm{IgE}$ bands have been inhibited (fig. 3). Since total serum IgE and grass pollen-specific IgE tests in the patient were unchanged, there was no unspecific IgE scavenger function of the buckwheat solution (data not shown). 


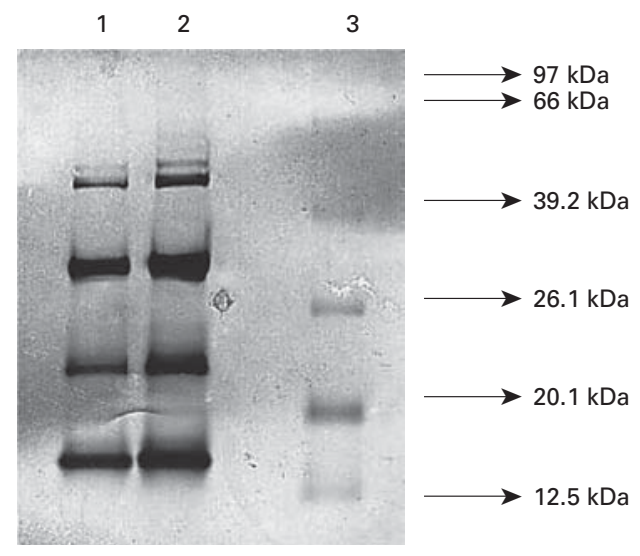

\section{Discussion}

The poppy flower is a member of the botanical family Papaveraceae. Poppy seeds and poppy oil are used as a condiment with baked goods and for cooking. We reported here a case of severe poppy seed anaphylaxis in a 17year-old female. The allergological workup included prick tests, CAP-FEIA and open oral food challenge tests. Allergy to poppy seed is a rare phenomenon. To the best of our knowledge, only 24 patients have been reported in the literature [3-10]. About $80 \%$ of these patients had an atopic background and other food allergies were present in two thirds of them. Though our patient did not show an atopic disease, the demonstration of a sensitization against rye pollen and grass pollen together with the elevated serum IgE suggests an atopic background.

Food challenge results have not been reported for any of these patients. In our patient, oral administration of up to $10 \mathrm{~g}$ of unground poppy seeds, as used for rolls and yoghurts, did not cause any symptoms. A 10-fold lower amount of ground poppy seeds, as used for traditional poppy seed cakes, caused a severe anaphylactic reaction. Therefore, the physical destruction of poppy seeds seems crucial for anaphylactic reactions. Most of the described poppy seed-allergic patients reacted to poppy cake probably containing ground poppy seeds, but allergic reac-

Fig. 2. Immunoblot detection of poppy seed allergens. Immunoblot analysis of $\operatorname{IgE}$ antibodies for allergens in poppy seed extract was performed to detect the molecular weight of the poppy seed allergens (diluted 1:2, lane 1 and 1:1, lane 2) recognized by the serum of our patient. The blot shows 4 distinct allergen bands with a size of about 15,23, 30 and $46 \mathrm{kDa}$ (lane 1 and 2) and the molecular weight marker (lane 3).

\begin{tabular}{|l|l|l|l|l|l|l|}
\hline A & B & C & D & E & F & G \\
\hline
\end{tabular}

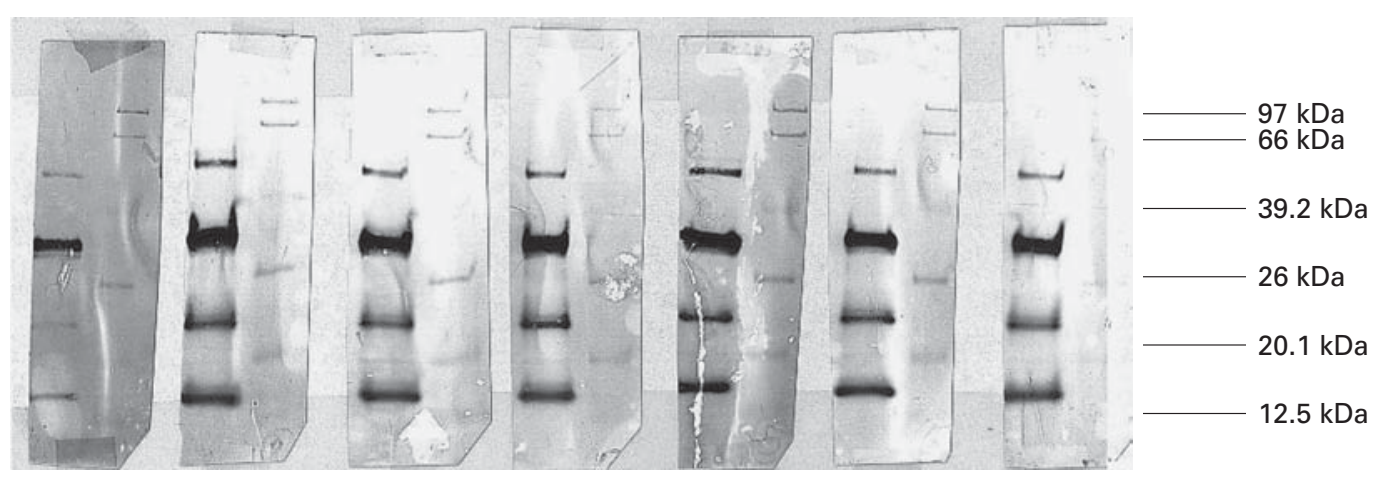

\begin{tabular}{|l|l|l|l|l|l|l|l|l|l|l|l|l|l|}
\hline PS & MW & PS & MW & PS & MW & PS & MW & PS & MW & PS & MW & PS & MW \\
\hline \multicolumn{2}{|c|}{$25 \mu \mathrm{g} / \mathrm{ml}$} & $10 \mu \mathrm{g} / \mathrm{ml}$ & $5 \mu \mathrm{g} / \mathrm{ml}$ & $2.5 \mu \mathrm{g} / \mathrm{ml}$ & $1 \mu \mathrm{g} / \mathrm{ml}$ & $0.5 \mu \mathrm{g} / \mathrm{ml}$ & \multicolumn{2}{|c|}{ No } & $\begin{array}{c}\text { Preincubation } \\
\text { with buckwheat }\end{array}$ \\
\hline
\end{tabular}

Fig. 3. Immunoblot inhibition of poppy seed allergens with buckwheat. IgE binding is shown before (lane $G$ ) and after preincubation of our patient's serum with buckwheat extract in different concentrations (lane A-F). PS = Poppy seed extract; $\mathrm{MW}=$ molecular weight marker. 
tions to probably unground poppy seeds from bread or ice cream have also been reported $[6,9,10]$. Some poppy seed allergens seem thermostable, as prick tests were positive with raw and baked material [7]. Following our advice to strictly avoid any future contact with poppy seeds, our patient remained free of allergic symptoms and did not have any further problems.

Cross-reactivity between poppy seed and sesame, hazelnut, rye grain and kiwi fruit has been identified and described in poppy seed-allergic patients $[11,12]$. Therefore, in our patient, sensitizations to sesame and hazelnut may be expected from cross-reactivity to poppy seed. The high titer sensitization against buckwheat led to the hypothesis of buckwheat being a previously unrecognized cross-reactive food to poppy seed. CAP inhibition and immunoblot inhibition experiments in serum from our patient demonstrated the novel identification of the crosssensitization to buckwheat. The clinical relevance of this laboratory finding could not be evaluated as the patient was not interested in further oral challenge tests.

Buckwheat, Fagopyrum esculentum, belongs to the Polygonaceae family. It is neither botanically related to grain (such as wheat or barley) nor to grass (such as rye). Buckwheat is mostly used as a replacement for grain in food for preparing a variety of baked products. Fagopyrin-induced photosensitization following ingestion of entire plants has been described in animals but not in man. However, asthma and food allergy have been described in humans after exposure or ingestion of buckwheat [1317]. The newly observed cross-sensitization between poppy seeds and buckwheat connects two botanically unre- lated, relatively distant species - Papaveraceae (P. somniferum) and Polygonaceae (F. esculentum).

The opium poppy plant, $P$. somniferum $\mathrm{L}$., is a source for poppy seeds and poppy seed oil, but not only. P. somniferum L. produces copious amounts of a viscous latex, which contains several important alkaloids such as morphine. In contrast to the latex mass known as opium, mature seeds lack alkaloids and are not narcotic. Since our patient with poppy seed anaphylaxis might be at risk following the therapeutic use of opioid analgesics, we decided to check for cross-sensitizations between poppy seeds and proteins from freshly drawn opium poppy latex milk and opium. However, a cross-sensitization to opium latex or raw opium could not be demonstrated by CAP inhibition. SPT with opium are not useful, as opiates cause nonspecific wheals by direct degranulation of mast cells [18].

In conclusion, the preparation of poppy seeds, whether ground or unground, can be a potent elicitor of anaphylactic reactions and in at least some poppy seed-allergic patients buckwheat must be considered as a novel cross-reactive allergen.

\section{Acknowledgments}

The excellent technical assistance of Sonja Maier and Gabi Weimer is thankfully acknowledged. The authors thank Prof. Dr. Meinhart H. Zenk from the Institute of Pharmaceutical Biology (Ludwig Maximilians University Munich) for providing latex and serum preparations of $P$. somniferum and contributing his botanical expertise.

\section{References}

1 Zenk MH: Über das Opium, das den Schmerz besiegt und die Sucht weckt. Bayerische Akademie der Wissenschaften. Munich, Beck'sche Verlagsbuchhandlung, 1993, pp 98-124.

2 Laemmli UK: Cleavage of structural proteins during the assembly of the head of bacteriophage T4. Nature 1970;227:680-685.

3 Jensen-Jarolim E, Gerstmayer G, Kraft D, Scheiner O, Ebner H, Ebner C: Serological characterization of allergens in poppy seeds. Clin Exp Allergy 1999;29:1075-1079.

4 Wagner G, Ring J: Anaphylaktische Reaktionen durch Nuss- und Mohnallergie. Notfallmedizin 1981;7:694-696.

5 Braun W, Kovary PM: Mohnallergie. Z Hautkr 1988:63:344

6 Kalyoncu AF, Stalenheim G: Allergy to poppy seed. Allergy 1993;48:295.

7 Frantzen B, Bröcker EB, Trautmann A: Immediate-type allergy caused by poppy seed. Allergy 2000;55:97-98.
8 Crivellaro M, Bonadonna P, Dama A, et al: Severe systemic reactions caused by poppy seed. J Investig Allergol Clin Immunol 1999;9: 58-59.

9 Gloor M, Kägi M, Wüthrich B: Mohnsamenanaphylaxie. Schweiz Med Wochenschr 1995; 125:1434-1437.

10 Vocks E, Seifert H-U: Mohnallergie - eine seltene Entität? Allergologie 1987;10:503-504.

11 Seifert HU, Seifert B, Düngemann H, Vocks E, Borelli S, Gugger A: Immunologische Kreuzreaktionen bei Nüssen, Roggenmehl, Kiwi, Sesam und Mohnsamen. Allergologie 1988;11: 169-172.

12 Vocks E, Borga A, Szliska C, et al: Common allergenic structures in hazelnut, rye grain, sesame seeds, kiwi, and poppy seeds. Allergy 1993;48:168-172.
13 Park HS, Nahm DH: Buckwheat flour hypersensitivity: an occupational asthma in a noodle maker. Clin Exp Allergy 1996;26:423-427.

14 Choudat D, Villette C, Dessanges JF, et al: Occupational asthma caused by buckwheat flour. Rev Mal Respir 1997;14:319-321.

15 Schumacher F, Schmid P, Wüthrich B: Sarrazin allergy: a contribution to buckwheat allergy. Schweiz Med Wochenschr 1993;123:15591562.

16 Schiffner R, Przybilla B, Burgdorff T, Landthaler M, Stolz W: Anaphylaxis to buckwheat. Allergy 2001;56:1020-1021.

17 Cooper MR, Johnson AW: Poisonous Plants in Britain and Their Effects on Animals and Man. London, Her Majesty's Stationery Office, 1984, p 305.

18 Nasser SM, Ewan PW: Opiate-sensitivity: clinical characteristics and the role of skin prick testing. Clin Exp Allergy 2001;31:1014-1020. 